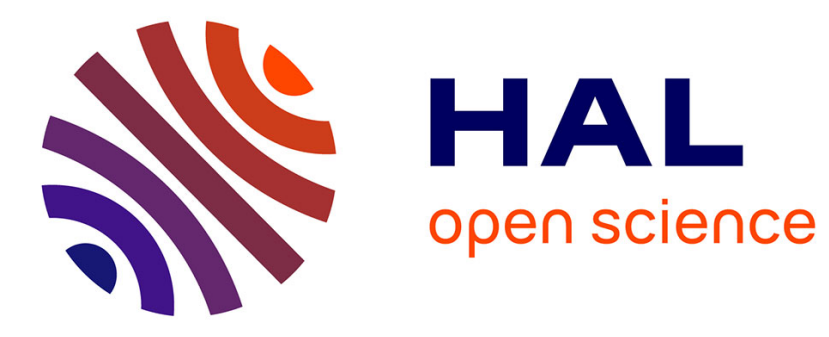

\title{
Exploring lay uncertainty about an environmental health risk
}

\author{
Maria Powell, Sharon Dunwoody, Robert Griffin, Kurt Neuwirth
}

\section{To cite this version:}

Maria Powell, Sharon Dunwoody, Robert Griffin, Kurt Neuwirth. Exploring lay uncertainty about an environmental health risk. Public Understanding of Science, 2007, 16 (3), pp.323-343. 10.1177/0963662507074491 . hal-00571129

\section{HAL Id: hal-00571129 \\ https://hal.science/hal-00571129}

Submitted on 1 Mar 2011

HAL is a multi-disciplinary open access archive for the deposit and dissemination of scientific research documents, whether they are published or not. The documents may come from teaching and research institutions in France or abroad, or from public or private research centers.
L'archive ouverte pluridisciplinaire HAL, est destinée au dépôt et à la diffusion de documents scientifiques de niveau recherche, publiés ou non, émanant des établissements d'enseignement et de recherche français ou étrangers, des laboratoires publics ou privés. 


\title{
Exploring lay uncertainty about an environmental health risk
}

\author{
Maria Powell, Sharon Dunwoody, Robert Griffin and Kurt Neuwirth
}

How do laypeople perceive uncertainties about environmental health risks? How do risk-related cognitions and emotions influence these uncertainties, and what roles do sociodemographic and contextual factors, risk judgments, and information exposures play? This study explores these questions using secondary analyses of survey data. Results suggest that uncertainty reflects individual-level emotions and cognitions, but may also be shaped by a variety of social and contextual factors. Emotions (worry and anger) are strongly associated with perceived uncertainty, and perceived lack of knowledge and perceived likelihood of becoming ill are weakly associated with it. Several demographic variables, information exposures, and risk judgment variables affect perceived uncertainty indirectly, primarily through perceived knowledge and emotions. These findings raise a variety of questions about the complex and dynamic interactions among risk contexts, socioeconomic factors, communication processes, perceived knowledge, emotions, and perceived uncertainties about risks.

\section{Introduction}

Uncertainty is becoming a key theme of our times as increasing rates of technological growth create uncertain or unknown risks to human and environmental health (Jaeger et al., 2001; Smithson, 1989). Scientists and policymakers often disagree about how serious health risks are and what actions should be taken to address them, and media stories and other information about risks typically reflect these controversies (Campbell, 1985; Friedman et al., 1999; Stocking and Holstein, 1993). Many scholars who study risk controversies describe and compare scientists' assessments of risk uncertainties, explore how public risk perceptions compare to scientific assessments, or assess how publics react to these assessments (Frewer et al., 2003; Johnson, 2003a, 2003b; Johnson and Slovic, 1998). Relatively few scholars have explored lay publics' risk uncertainty perceptions per se, or what factors shape these perceptions.

In this study, we examine how a variety of individual and social factors shape public uncertainty perceptions about an environmental health risk. Our primary goal is to begin to understand how laypeople perceive uncertainties about health and environmental risks and what shapes those perceptions.

Laypeople acquire information about environmental risks from first-hand experiences and from a variety of mediated and interpersonal sources (O'Keefe et al., 2002; Rimal et al., 
1999). What people know and don't know about risks, as well as their risk-related emotions, can affect their interpretations of environmental risk information, their risk perceptions, and whether or not they seek out further information (Griffin et al., 1999). Socioeconomic, cultural, and contextual factors, moreover, can shape these perceptions and behaviors in significant ways (Howel et al., 2002; Irwin and Wynne, 1996; Lopez, 2002). How do cognitive and emotional factors, along with social and contextual factors, influence laypersons' perceptions of risk uncertainties? In this exploratory study, we address these questions.

\section{What is perceived uncertainty?}

Scholars from various fields approach uncertainty in a variety of ways - as an individual-level cognition, as an individual or organizational probability assessment, as a social, political, or cultural construction, or as combinations of these (Babrow et al., 1998; Brashers et al., 2000a, 2000b; Bradac, 2001; Frewer et al., 2002, 2003; Friedman et al., 1999; Johnson, 2003a, 2003b; Rowsell et al., 2000). Some scholars address uncertainty perceptions generally, while others address perceived uncertainties about risks specifically. Regardless of approach, several common themes emerge in this literature about what perceived uncertainty might entail, including (1) the perception of "not knowing," (2) emotions, and (3) communication processes. In the following section, we outline these three themes.

\section{Lack of knowledge or "not knowing"}

The most common theme among previous studies on uncertainty is the assumption that uncertainty reflects a person's lack of knowledge or "not knowing"-i.e., not knowing about one's own knowledge, others' knowledge, the state of knowledge "out there" in the world, or a combination of these. Psychological theories, for example, emphasize the importance of knowledge about the world to people's ability to survive and imply that knowledge (and, thus, its absence) is central to uncertainty. Earlier psychological studies of uncertainty (Festinger, 1954, 1957; Heider, 1958), as well as more recent studies (Sorrentino and Roney, 2000; Weary and Edwards, 1994, 1996; Weary and Jacobson, 1997), assume that uncertainty is an individual-level cognitive perception based on perceived lack of knowledge.

Uncertainty studies focused on risk often approach uncertainty as a reflection of laypersons' probabilistic judgments about some risk event or outcome happening (Frewer et al., 2003; Kahneman and Tversky, 1982a, 1982b). Probability judgments are types of "not knowing." Communication theories on uncertainty, such as uncertainty management theory (Brashers et al., 2000a, 2000b), uncertainty reduction theory (Berger, 1987) and problematic integration theory (Bradac, 2001), similarly, assume that probability assessments and "not knowing" are made up, in part, of perceived uncertainty. Brashers (2001), for example, says, "Uncertainty exists when details of situations are ambiguous, complex, unpredictable, or probabilistic ... when people feel insecure in their own state of knowledge or the state of knowledge in general" (p. 478).

A variety of other studies connect uncertainty to "not knowing." Communication scholars Einsiedel and Thorne (1999), for example, propose eight "dimensions of uncertainty" that describe different kinds of situations in which people "know they do not know" about a scientific or risk issue (p. 43):

1. I don't know anything about X; I will leave it to experts to tell me what I need to know.

2. I don't know about X; that's okay because it isn't that important or relevant to me. 
3. I don't know much about X, and I don't want to know any more.

4. I don't know much about $X$ and I want (or need) to know more, so I intend to learn more about it.

5. I don't know about X; no one else knows much (or anything definitive) about X, and there's not much we can do about it.

6. I don't know about X, but my friends and family know quite a bit about it; I'd better find out more about it, or I might be left out.

7. I don't know about X and I don't have the skills to find out; therefore, I can't really learn more about it until I acquire these skills.

8. I don't know about X, and I can't get the information so I can't really learn more about it until the information becomes more accessible.

Many sociological and community-based health risk studies loosely connect laypersons' perceived uncertainties about health risks to different kinds of "not knowing." For example, case studies of communities dealing with contaminated air, water, or soil problems address how laypeople perceive uncertainties about these issues in complex, "real-world" contexts (Brown and Mikkelson, 1990; Bush et al., 2001; Hallman and Wandersman, 1992). In these contexts, laypersons' uncertainties about environmental contaminants are often based on a sense of "not knowing" about these contaminants because they are invisible, because health problems related to them may not show up for years, and/or because information about them isn't available or is not provided by authorities (Adeola, 2000; Brown and Mikkelson, 1990; Hallman and Wandersman, 1992; Irwin and Wynne, 1996).

\section{Emotions}

Most uncertainty scholars focus on uncertainty's cognitive components. A few, however, directly or indirectly address emotional components. Problematic integration theory (Bradac, 2001) and uncertainty management theory (Brashers, 2001) both connect emotions to what they call the "evaluative" or "appraisal" components of uncertainty, which they suggest are linked to cognitive, probabilistic components. Many community risk studies also connect lay perceptions of uncertainty about risks to worry, anger, stress and anxiety about these risks (Adeola, 2000; Brown and Mikkelson, 1990; Hallman and Wandersman, 1992; Matthies et al., 2000).

Interestingly, although a few risk perception scholars link uncertainty to emotions (Griffin et al., 1999; Slovic, 1992), most science and risk uncertainty studies do not make this link-possibly because they assume that lay uncertainty primarily reflects scientific uncertainty and/or probability assessments (Frewer et al., 2001, 2003; Johnson, 2003a; Johnson and Slovic, 1998; Miles and Frewer, 2003). Some of these studies, however, connect perceived uncertainty to government trust, which is often related to worry or anger (Johnson, 2003a; Johnson and Slovic, 1998). Slovic and colleagues (see, for example, Finucane et al., 2000; Slovic et al., 2005) urge scholars to begin considering the influence of affect in risk decision making and have begun work in this area themselves.

\section{Communication processes}

Several uncertainty studies relate communication processes explicitly to the creation and resolution of uncertainty. Communication theories on uncertainty, not surprisingly, are based on the premise that the creation, management, and resolution of uncertainty involve communication between at least two people (Berger, 1987; Bradac, 2001; Brashers, 2001). Uncertainty reduction theory proposes communicative and noncommunicative causes and consequences of uncertainty (Berger, 1987). Several of Einsiedel and Thorne's (1999) “dimensions of 
uncertainty" are related to perceptions about communication issues, such as information availability and ability to gather information.

\section{Gaps in previous approaches to risk uncertainty}

Although the studies reviewed above provide much insight into uncertainty perceptions, several gaps remain. Many studies do not clarify who is perceiving uncertainty. Moreover, several factors that might shape uncertainty perceptions are not clearly addressed, including (1) "knowing" or perceived knowledge, (2) the role of trust, (3) risk judgments and issue relevance, (4) information exposures and interpersonal discussion, and (5) sociodemographic and contextual factors. We address each of these issues below.

\section{Who is perceiving uncertainty?}

In the psychological and communication uncertainty literature, for the most part, it is clear that uncertainty refers to individuals' states of mind. Einsiedel and Thorne's uncertainty dimensions, for example, explicitly state that people are uncertain when they feel they don't know. Brashers' uncertainty management theory, likewise, makes it clear that "a person who believes himself or herself to be uncertain is uncertain" (2001: 478). In other words, both these definitions assume that uncertainty is perceptual. In this study, similarly, we conceptualize uncertainty as an individual's perception that he/she is uncertain.

Many studies that address lay uncertainty about risks, however, are not clear about what uncertainty is and/or who perceives it. Uncertainty is assumed to be "out there" in the world, rather than the result of a perceptual process. Several studies assume that uncertainty reflects scientists' uncertainty about technical aspects of the risk at hand, and then attempt to measure individuals' knowledge of — or reactions to — that uncertainty. Frewer et al. (2003), for example, measure people's responses to scientists' uncertainty statements. Johnson (2003a, 2003b) and Johnson and Slovic (1995, 1998), similarly, assess responses to statements illustrating scientific uncertainties about risks, but do not assess whether or not people themselves feel uncertain about the risks or what the nature of their uncertainty might be. Unfortunately, by approaching uncertainty only as an "objective" state of the world "out there"-a state most accurately defined by scientists - these approaches implicitly support a "deficit model" of public understanding of risks (Irwin and Wynne, 1996; Wynne, 2001). Moreover, they tell us little about laypersons' uncertainty perceptions, how they are constructed, or what factors shape them.

Kahneman and Tversky many years ago offered a conceptual framework that may serve scholars interested in better understanding the meaning given by individuals to uncertainty. In a seminal article in the early 1980s (Kahneman and Tversky, 1982a), they explored a variety of dimensions of uncertainty and suggested two loci of attribution: external and internal. In the first, individuals attribute the presence of uncertainty to the external world; thus, lay acknowledgement of the presence of uncertainty in scientific knowledge about a risk could be categorized as a form of "external uncertainty." The second type of attribution, internal, reflects a person's tendency to locate the source of uncertainty in him/herself. That is, one may register a high state of uncertainty because one feels uninformed about the risk.

\section{Perceived knowledge}

Few studies address what people $d o$ know about environmental risks and/or how this knowledge is associated with their uncertainties, or what they do not know. Yet perceived and/or actual 
knowledge are likely to play roles in uncertainty perceptions. In fact, uncertainty measurements in many risk studies seem to reflect what people know (or think they know) as much as what they don't know (Frewer et al., 2002; Johnson, 2003a, 2003b; Miles and Frewer, 2003). Although few studies connect knowledge to uncertainty, it makes sense that what people know might be closely linked to what they don't know and to their uncertainties. Like scientists, people make probability judgments based on what they know as much as or more so than on what they don't know (Heyman et al., 1998). Also, evaluative and emotional components of lay uncertainties about risks are likely to be based on what laypersons know about the risks. For example, people are less likely to raise questions or worry about risks they do not know about, and the nature of people's knowledge about risks is likely to be related to the types and levels of emotions they feel about those risks.

\section{Trust}

Because trust is often connected to perceptions about who controls and creates information, trust perceptions are likely to be associated with communication processes. In the case of environmental toxins, which are usually invisible, the public depends on scientists and experts from government or academia to measure the toxins, assess potential risks related to them, and communicate what they know or don't know about the risks. Consequently, trust in government officials and regulatory agencies responsible for communicating and managing risks can play a critical role in shaping uncertainty perceptions (Cvetkovich et al., 2002; Freudenburg and Pastor, 1992; Hallman and Wandersman, 1992; Wynne, 1980).

Although few scholars have built measures of trust explicitly into their studies of uncertainty perceptions, some may have done so implicitly (Frewer et al., 2002; Johnson, 2003b; Johnson and Slovic, 1995, 1998). Johnson (2003b), for example, concludes that "it is still unclear whether uncertainty in risk estimates is an independent issue in risk communication, or whether attitudes toward it merely reflect other attitudes, such as whether one can control risks to oneself or trusts that source of uncertain risk estimates" (p. 788).

\section{Risk judgments and issue importance}

Previous studies connect a variety of risk judgments to worry or fear about risk (Griffin et al., 1999; Slovic, 1992), yet most have left largely unexplored the relationships between various risk judgments, such as perceived risk likelihood and severity, and perceived uncertainty. Risk likelihood reflects a person's perception of the likelihood that a risk will affect him or her. In other words, it is essentially a probability assessment. Given this, it seems likely that it might be related to perceived uncertainty. Slovic's psychometric paradigm, moreover, suggests that perceived risk likelihood, perceived threat to future generations, and perceived potential for catastrophic outcomes, all types of risk judgments, are likely to heighten negative emotions about risks. Through emotions, or directly, risk judgments could affect perceived uncertainties about risks. The perceived importance of a risk issue also seems likely to be connected to perceived uncertainty about it. People are likely to be more concerned about issues that are important to them. Further, risk communication studies suggest that when an issue is more important to people, they are likely to process information about it more systematically—and therefore they may gain more knowledge (Griffin et al., 1999; Petty and Cacioppo, 1981).

\section{Information exposures and interpersonal discussion}

Few risk uncertainty studies consider communication variables such as exposures to mass media, specialized risk information, or interpersonal discussions. Yet communication scholars tie 
uncertainty explicitly to interactions with information from mass media and other sources. Einsiedel and Thorne (1999), for example, assert that to understand laypersons' uncertainties and how they manage them, we need to understand what kinds of information they are exposed to:

To understand the context within which various publics navigate through uncertainties in this information environment, we need to discuss the role and nature of information sources that contribute to it. A significant source of information for the public, of course, is the mass media. Quite often, people's knowledge of science and technology issues is influenced by mass media content. (p. 52)

As these authors note, mass media may not determine how people think about an issue in a linear fashion, but over time these channels may be an important source of information and may influence people's knowledge of and perceptions about science and technological issues. Other scholars, similarly, discuss the complex ways that interactions with media can affect attitudes about science and personal and social risk perceptions (Coleman, 1993; Friedman et al., 1999; Hansen, 1993; Hornig Priest, 2001).

In situations in which an environmental contamination problem or other hazard has already occurred, specialized information from government and other organizations could also affect public uncertainty perceptions. In these contexts, people often seek out information from government and activist groups, and in some cases citizens organize and disseminate their own information, e.g., through such vehicles as brochures and press releases (Brown and Mikkelson, 1990; DiPerna, 1985; Hallman and Wandersman, 1992). Outreach materials from citizen groups and government agencies may include different-and sometimes conflicting - information about contaminants and health risks. Perceived conflicts in information content from different sources can add to community members' uncertainties. Moreover, citizens' knowledge and experiences can accentuate the gaps and uncertainties in expert knowledge, sometimes by calling attention to previously unrecognized or ignored uncertainties about the risk. As Bush et al. (2001) note:

The public doesn't assimilate scientific information in a passive way, but the social validation and legitimization of expert information is actively negotiated in relation to a range of resources, including experiential and local knowledge ... commentators from many backgrounds have demonstrated growing public discontent with scientific information, particularly when expert accounts of physical reality conflict with local knowledge and personal experience. (p. 215)

People also talk to their family, friends, and co-workers about environmental and health problems they face in their personal lives or in broader communities. Interpersonal discussions can influence laypersons' awareness of these issues, their risk perceptions, their knowledge levels, and their subsequent information seeking (Chaffee and Mutz, 1988; Coleman, 1993; Valente and Saba, 1998). All of these factors could influence perceived uncertainties in a variety of direct and indirect ways. For example, if the content of interpersonal discussions conflicts with scientific, mass media, and government risk information, uncertainties and confusion about the risks may be compounded. On the other hand, people may choose to believe certain sources and not others, which might reduce their uncertainties and confusion about the risks.

\section{Sociodemographic and contextual factors}

People with different socioeconomic backgrounds often have different experiences with risks. For example, minorities and the poor are more likely to be exposed to environmental health 
risks than are the wealthy and white people (Bullard, 1990; Lopez, 2002; Mohai and Bryant, 1992). Different income and education levels, experiences, and risk exposure levels can affect perceptions related to perceived uncertainty, such as how much people think they know, how efficacious they feel, and their levels of anger and worry about risks (Arcury et al., 2002; Lindbladh and Lyttkens, 2003). Moreover, people in different social-structural and geographical locations often have different kinds of knowledge about environmental risks based in part on different experiences (Harding, 1998; Irwin and Wynne, 1996).

\section{The present study}

\section{The risk issue: consumption of contaminated Great Lakes fish}

In the Great Lakes region of North America, sport fishing and eating fish are extremely popular activities for many different kinds of people (Chiarappa and Szylvian, 2003). Restaurants and fish markets throughout the region sell a variety of fish from the Great Lakes. Self-caught fish are an important and free source of food for some low-income people, particularly in large urban areas on Great Lakes shores, and many subsistence anglers are minorities (Beehler et al., 2001; Burger et al., 1999).

Unfortunately, Great Lakes waters and fish are contaminated with a variety of synthetic chemicals, several of which are associated with reproductive, developmental, neurological, and/or immune system problems in humans and animals (e.g., mercury, PCBs [polychlorinated biphenyls], dioxins, pesticides) (Courval et al., 1999; Humphrey et al., 2000; Jacobson and Jacobson, 1996; Rice, 1995). Many complex scientific uncertainties remain about the nature and extent of the health problems related to Great Lakes fish consumption (Darvill et al., 1996; Shatenstein et al., 1999). While aware of these uncertainties, public health agencies in the Great Lakes region have issued public warnings about the potential risks related to eating Great Lakes fish. Unfortunately, however, studies indicate that fish consumption advisories do not reach many anglers and their families, and when advisories are received, they are often discounted or ignored (Burger, 2000; Tilden et al., 1997). Moreover, little to nothing is known about awareness, knowledge, and uncertainties among the general public (including non-anglers) about the risks from eating Great Lakes fish.

\section{Research questions and hypotheses}

Research question 1: How do knowing and not knowing (need to know) influence perceived uncertainty about the risks from eating contaminated Great Lakes fish?

Most previous studies assume that uncertainty reflects some kind of "not knowing." If this assumption is correct, then lower perceived knowledge levels should be associated with perceived uncertainty. Moreover, some psychologists propose that people are uncertain when they feel that their knowledge isn't up to par with what they should know or what they need to know (Festinger, 1954; Weary and Edwards, 1996). Griffin et al. (1999), similarly, suggest that uncertainty is related to "judgmental confidence," or having a sufficient degree of confidence that one has enough knowledge to make a decision (Eagly and Chaiken, 1993). In other words, perceived need to know is a type of "not knowing," and is likely to be connected to perceived uncertainty. We propose the following hypotheses:

H1: Perceived knowledge will be negatively associated with perceived uncertainty.

H2: Perceived need to know will be positively associated with perceived uncertainty. 
Research question 2: How do emotions (anger and worry) relate to perceived uncertainty about the risks from eating contaminated Great Lakes fish?

Although most previous risk uncertainty studies overlook the role of emotions, communication scholars have connected emotions-particularly negative emotions-to perceived uncertainty (Griffin et al., 1999). Similarly, while making no predictions about the causal order of this relationship, we propose that negative emotions (anger and worry) will be associated with perceived uncertainty:

H3: Negative emotions will be positively associated with perceived uncertainty.

The third research question explores several individual and social factors not clearly addressed in previous studies. It is an exploratory question; no hypotheses are proposed:

Research question 3: How do socioeconomic factors, fish consumption behaviors, information exposures and interpersonal discussions, issue importance, government trust, and risk judgments affect perceived uncertainty?

\section{Methods}

\section{Data gathering}

This study is based on secondary analysis of survey data gathered by Griffin, Dunwoody and Neuwirth (1999). The project was funded by the Federal Agency for Toxic Substances and Disease Registry (ATSDR). Respondents were drawn from two metropolitan Midwestern cities on the shores of the Great Lakes-Milwaukee, Wisconsin, and Cleveland, Ohio. The initial questionnaire was developed after conducting four focus groups with a random sample of Milwaukee area residents in the spring of 1996, followed by a pre-test on 301 students at three universities in Wisconsin and Ohio. The Wisconsin Survey Research Laboratory gathered the data from October 1996 to March 1997 by employing telephone surveys of adult residents who were reached through random digit dialing (RDD).

The full study from which these data were taken surveyed a representative sample of Cleveland and Milwaukee residents annually for three years (1996, 1997 and 1998) about their perceptions of three risks: eating possibly contaminated fish from the Great Lakes, drinking tap water drawn from the lakes, and potential health problems posed to the lakes themselves by urbanization, industry, etc.

The current analysis utilizes a subset of 528 respondents from wave 2 (1997) who were queried about the risks of eating sport-caught fish. Wave 2 was chosen because that year's questionnaire included media exposure and media attention items that were focal independent and dependent variables in the study. The sample was derived as follows:

Respondents interviewed in wave 1 (1996) were placed in the fish risk path if they reported either eating Great Lakes fish or avoiding at least some fish for health reasons. All other respondents were randomly assigned to either the tap water or Great Lakes ecosystem study. Researchers attempted to re-interview as many of the wave 1 respondents as possible for wave 2. Since attrition is a natural part of panel studies, new respondents were added to the wave 2 panel via random digit dialing. All data analyses controlled for survey sensitization to assure that re-interviewed panelists did not differ significantly from new panelists.

The combined response rate for the initial wave of the survey, in 1996, was 55.2 percent with a total of 1,123 respondents. Of this group, 634 were in the fish risk path. In wave 2 , researchers successfully re-interviewed 66 percent of the first-wave respondents and an 
additional 108 new respondents were added to the fish path through RDD. As a result, the final $N$ of fish path respondents in wave 2 summed to 528 .

\section{Conceptualization and measurement of variables}

\section{Perceived uncertainty}

In this study, we assume that uncertainty is an individual's perception. In other words, we adopt an approach to perceived uncertainty similar to that proposed by Brashers, who states that "a person who believes himself or herself to be uncertain is uncertain" (2001: 478). The uncertainty assessment in this study is based on respondents' self-reports rather than on external assessments by others and reflects their own quantitative assessment of whatever they are uncertain about. In other words, it reflects self-perceived level or quantity of uncertainty but not the content of uncertainty. Perceived uncertainty was assessed with one question: "When you think about the possible health risks posed to you from eating Lake Michigan/Erie fish, how much uncertainty do you feel?" (0-10 response option, where 10 means "a lot" and 0 means "not at all").

While we would have preferred to utilize a multi-item or otherwise more sophisticated measure of perceived uncertainty, the survey on which this study was based was not intended to explore that concept and, therefore, included only one uncertainty question. While we acknowledge the limitations of a one-question measure, we propose that the examination of how a variety of factors relate to even this rudimentary measure of perceived uncertainty can reveal quite a bit about what this perception might include and what factors might shape it.

\section{Perceived current knowledge, sufficient protection knowledge, and need to know}

Perceived current knowledge reflects how much people think they know about the fish risk, regardless of its accuracy. Scholars have proposed that using assessments of knowledge that reflect what people "think they know" may be more useful for understanding risk perceptions and information use and processing than assessments of "right" or "wrong" knowledge (Ferguson, 2001; Frewer et al., 1994; Thompson and Kruglanski, 2000; Wood et al., 1995) or assessments of how well knowledge parallels what scientists know (Irwin and Wynne, 1996). Ferguson (2001), for example, differentiates "raw knowledge" ("accurate" knowledge) from "calibrated" knowledge (what people think they know) and argues that risk knowledge and risk perceptions are not reliably associated in risk studies, in part, because "raw" rather than "calibrated" knowledge scores are often used. Similarly, Wood et al. (1995) propose that what people think they know is more likely to be connected to what they think, feel, and do than is "correct" knowledge.

In this study, we conceptualize perceived knowledge as how much a person thinks he or she knows about the fish risk, taking into account any kind of knowledge the person thinks is relevant to the issue. To assess this, respondents were presented with the following question: "Now, I would like you to rate your own knowledge about this risk. Please use a scale of zero to 100 , where zero means knowing nothing and 100 means knowing everything you could possibly know about this topic. Using this scale, how much do you think you currently know about the risk from eating Lake Michigan/Erie fish?" (Respondents picked a number from 0 to 100.)

Sufficient protection knowledge reflects what people feel they need to know to deal adequately with the fish risk beyond what they already know about it. The sufficient protection knowledge question was asked directly after the knowledge question, as follows: "Think of 
that same scale again. This time, we would like you to estimate how much knowledge you would need to deal adequately with the possible risk from eating Lake Michigan/Erie fish. Of course, you might feel you need the same, more, or possibly even less, information about this topic. Using a scale of zero to 100, how much information would be sufficient for you, that is, good enough for your purposes?" (Respondents picked a number from 0 to 100.)

Need to know is the difference between a respondent's sufficient protection knowledge level and his/her perceived current knowledge level. The variable is analogous to Griffin et al.'s (1999) "information sufficiency." It reflects "not knowing" about a specific aspect of the issue (self-protection). Need to know was calculated by subtracting each respondent's perceived current knowledge level from his/her sufficient protection knowledge level.

\section{Risk emotions, risk judgments, issue importance, and government trust}

Two emotions-worry and anger-are included in these analyses. We view worry in this study as an affective state that reflects anxiety about the risk (Griffin et al., 1999; Nerb and Spada, 2001; Smith et al., 1993). Anger is conceptualized as a reflection of a more externally directed, assertive affective state (i.e., outrage) about the risk that is associated with assigning responsibility for the risk issue (Griffin et al., 1999; Nerb and Spada, 2001). Worry and anger were assessed with the following question (asked separately for each emotion): "When you think about the possible health risks posed to you from eating Lake Michigan/Eric fish, how much worry/anger do you feel?" (0-10 response options, where 10 means "a lot" and 0 means "not at all"). Because correlations between anger and worry and other key study variables are nearly identical in direction and strength, they are combined into an additive index called "emotions" (standardized alpha $=.82$ ).

Three risk judgments are assessed in this study: perceived likelihood, perceived future threat, and perceived seriousness. They are not combined because they reflect conceptually distinct types of perceptions and/or probability assessments. Perceived likelihood (of becoming ill from eating contaminated fish) reflects a person's judgment about the likelihood (or probability) that he or she personally will become ill from eating contaminated Great Lakes fish, and was assessed with the following question: "How likely are you to become ill in the future from eating contaminated fish caught in Lake Michigan/Erie?" (0-10 response option, where 10 means "a lot" and 0 means "not at all"). Perceived future threat (to future generations) is a judgment about the likelihood that future generations will face health problems because of fish contamination. It is a societal level probability judgment. To assess this, respondents were asked to react to the following statement: "Contamination of fish in Lake Michigan/Erie threatens the health and safety of future generations" (1-5 response option, where 1 means strongly disagree, and 5 means strongly agree). Perceived seriousness (of illness related to fish contamination) is a person's judgment about the nature and the severity of any illness that he/she thinks he/she might experience as a result of eating contaminated fish, and it was assessed with the following question: "If you were to become ill from eating contaminated Lake Michigan/Erie fish, how serious do you think this illness would be?" (0-10 response option, where 10 means "a lot" and 0 means "not at all").

Issue importance is conceptualized as a reflection of the perceived relevance of the fish risk issue to the respondent. To assess this, respondents were asked: "How important to you is the matter of your eating contaminated Lake Michigan/Eric fish?" (0-10 response option, where 10 means "a lot" and 0 means "not at all").

Government trust reflects respondents' perceptions about the government. To assess this, respondents were asked to react to three statements: (1) Government is doing a competent job of protecting people's health from risks related to eating contaminated Lake Michigan/Erie 
fish. (2) I trust government to protect me from risks related to eating contaminated Lake Michigan/Eric fish. (3) Government officials care about the health and safety of people like me. (1-5 response option, where 1 means strongly disagree, and 5 means strongly agree.) These three variables were combined into an additive index (standardized alpha $=.77$ ).

\section{Information exposures, interpersonal discussion, fish consumption, and sociodemographics}

For all mass media channels, exposure reflects the amount of time per week a person watches television news, reads the newspaper, or listens to news or information programs on the radio. As with the risk judgment measures, we kept these items separate in order to explore their individual contributions. Interpersonal discussion exposure reflects the frequency of conversations with friends, co-workers and family about fish contamination and/or about the lakes in general. Discussion about fish contamination and discussion about the lakes in general were combined into an additive index called "discussion exposure" (standardized alpha = .78). Exposure to fish advisories reflects whether or not respondents had seen a fish advisory issued by government agencies (24.6 percent said they had seen advisories). To assess fish consumption, respondents were categorized into those who eat fish and do not avoid any (44.3 percent), those who eat fish but avoid some fish (17.8 percent), and those who avoid all fish because of health risk concerns (28.4 percent); these categories were dummy-coded. Demographic variables, including city residence (49 percent from Milwaukee, 51 percent from Cleveland), age, education, gender, race, and income, were also assessed.

\section{Analyses}

The Statistical Package for the Social Sciences (SPSS) was used for all analyses. First, missing variables were replaced with the mean, and bivariate correlations were assessed among all variables to examine zero-order relationships. Ordinary least squares regressions (hierarchical) were used to examine research questions and to test hypotheses. In all analyses, sensitization for involvement in the first wave of the survey was controlled. Perceived uncertainty was regressed on all the variables, in the following order: (1) demographics; (2) fish consumption; (3) information exposures; (4) perceived current knowledge; (5) issue importance; (6) government trust; (7) risk judgments; (8) emotions; (9) sufficient protection knowledge.

The regression was also run separately with need to know (entered last) but excluding perceived knowledge and sufficient protection knowledge, since the measurement of need to know is a compilation of knowledge and sufficient protection knowledge. To explore the predictors to the key independent variables, current knowledge, need to know, and emotions were also regressed on the set of variables listed above. For regressions on uncertainty, both indirect (only demographics controlled) and direct (with all other variables controlled) Beta values were calculated. For current knowledge, need to know, and emotions, only direct Beta values were calculated.

\section{Results}

Table 1 shows descriptive statistics for all variables, and Table 2 shows regression on perceived uncertainty.

Research questions 1 and 2 examine how perceived knowledge, need to know, and emotions are related to perceived uncertainty. Results support all hypotheses. Supporting Hypothesis 1, 
Table 1. Descriptive statistics for all variables

\begin{tabular}{|c|c|c|c|c|}
\hline Variable & Percent & Mean & Standard deviation & Range \\
\hline City residence & 49\% Milwaukee & - & - & - \\
\hline Gender & $54 \%$ female & - & - & - \\
\hline Age (years) & - & 49.4 & & $20-92$ \\
\hline Education $^{\dagger}$ & - & 4.1 & & $1-6$ \\
\hline Income & - & $\$ 47,800 / \mathrm{yr}$ & & $\$ 2-300,000 / y r$ \\
\hline Minority & $18 \%$ & - & - & - \\
\hline Eats fish & $44.3 \%$ & - & - & - \\
\hline Avoids some fish & $17.8 \%$ & - & - & - \\
\hline Avoids all fish & $28.4 \%$ & - & - & - \\
\hline Newspaper & - & $3.96 \mathrm{hrs} /$ week & 3.94 & $0-35$ \\
\hline Television & - & $5.63 \mathrm{hrs} /$ week & 5.67 & $0-42$ \\
\hline Radio & - & $5.56 \mathrm{hrs} /$ week & 8.19 & $0-42$ \\
\hline Advisory & $24.6 \%$ (yes) & - & - & - \\
\hline Discussion & - & 4.54 & 1.38 & $2-8$ \\
\hline Issue importance & - & 6.61 & 3.15 & $0-10$ \\
\hline Government trust & - & 8.32 & 2.70 & $3-15$ \\
\hline Perceived likelihood & - & 3.37 & 2.79 & $0-10$ \\
\hline Perceived seriousness & - & 4.76 & 2.71 & $0-10$ \\
\hline Perceived future threat & - & 3.89 & .99 & $1-5$ \\
\hline Perceived current knowledge & - & 37.40 & 23.34 & $0-100$ \\
\hline Sufficient protection knowledge & - & 66.34 & 23.27 & $0-100$ \\
\hline Need to know & - & 28.97 & 26.84 & $-55-100^{*}$ \\
\hline Emotions & - & 9.66 & 6.06 & $0-20$ \\
\hline Percent uncertainty & - & 5.50 & 3.13 & $0-10$ \\
\hline
\end{tabular}

Education was collapsed into six categories: (1) eighth grade or less; (2) some high school; (3) high school graduate or GED certificate; (4) some technical school or vocational training, technical school graduate; or some college; (5) college graduate; (6) postgraduate or professional degree. The value given is the average using this scale.

"Need to know was calculated by subtracting current knowledge (range 0 to 100) from sufficient protection knowledge (range 0 to 100), so levels can be below zero in cases in which sufficient protection knowledge is less than current knowledge.

perceived knowledge is negatively associated with perceived uncertainty in the final equation ( $\beta=-.08, p=.03$ ). However, patterns in the regressions indicate that the relationship between knowledge and uncertainty is affected in complex ways by other variables. At the zero-order level, perceived knowledge is not associated with perceived uncertainty ( $r=.01$, n.s.). When demographics are controlled, its significance jumps, remaining positive but insignificant. When fish consumption variables are controlled, its direction reverses, although it is still insignificant. When information exposure variables are controlled, it jumps up in significance, remaining negative and nearing significance $(\beta=-.07, p=.11)$. It jumps to significance when emotions are controlled in the final model $(\beta=-.08, p=.03)$.

Supporting Hypothesis 2, perceived need to know is positively associated with perceived uncertainty $(\beta=.07, p=.04)$, and supporting Hypothesis 3 , negative emotions are strongly associated with perceived uncertainty $(\beta=.58, p<.001)$.

Research question 3 asks how socioeconomic factors, fish consumption, information exposures and interpersonal discussions, issue importance, government trust, and risk 
Table 2. Predictors to perceived uncertainty

\begin{tabular}{|c|c|c|c|}
\hline & \multicolumn{3}{|c|}{ Perceived uncertainty } \\
\hline & Indirect & Direct & Block $R^{2}$ \\
\hline \multicolumn{4}{|l|}{ Demographics } \\
\hline City & $-.11^{\mathrm{b}}$ & & \\
\hline \multicolumn{4}{|l|}{ Age } \\
\hline \multicolumn{4}{|l|}{ Gender } \\
\hline Education & $-.11^{\mathrm{c}}$ & & \\
\hline Income & $-.11^{\mathrm{c}}$ & & \\
\hline Minority & $.09^{\mathrm{c}}$ & & $.07^{\mathrm{a}}$ \\
\hline \multicolumn{4}{|l|}{ Fish consumption } \\
\hline Eat fish & $-.21^{\mathrm{a}}$ & & \\
\hline \multicolumn{4}{|l|}{ Avoid some fish } \\
\hline Avoid all fish & $.20^{\mathrm{a}}$ & & $.06^{\mathrm{a}}$ \\
\hline \multicolumn{4}{|l|}{ Information exposures } \\
\hline \multicolumn{4}{|l|}{ Newspaper } \\
\hline Television & $.15^{\mathrm{a}}$ & & \\
\hline \multicolumn{4}{|l|}{ Radio } \\
\hline \multicolumn{4}{|l|}{ Advisory } \\
\hline Discussion & $.20^{\mathrm{a}}$ & & $.04^{\mathrm{a}}$ \\
\hline Current knowledge $^{*}$ & & $-.08^{\mathrm{c}}$ & .004 \\
\hline Issue importance & $.52^{\mathrm{a}}$ & $.13^{\mathrm{a}}$ & $.19^{\mathrm{a}}$ \\
\hline Government trust & $-.19^{\mathrm{a}}$ & & $.01^{\mathrm{c}}$ \\
\hline \multicolumn{4}{|l|}{ Risk judgments } \\
\hline Perceived likelihood & $.33^{\mathrm{a}}$ & $.07^{\mathrm{c}}$ & \\
\hline Perceived seriousness & $.39^{\mathrm{a}}$ & & \\
\hline Perceived future threat & $.42^{\mathrm{a}}$ & & $.06^{\mathrm{a}}$ \\
\hline Emotions & $.73^{\mathrm{a}}$ & $.58^{\mathrm{a}}$ & $.14^{\mathrm{a}}$ \\
\hline Sufficient protection knowledge ${ }^{*}$ & $.18^{\mathrm{a}}$ & & \\
\hline Need to know** & $.19^{\mathrm{a}}$ & $.07^{\mathrm{c}}$ & $.004^{\mathrm{c}}$ \\
\hline Total adjusted $\mathrm{R}^{2}$ & & & .55 \\
\hline
\end{tabular}

All coefficients are standardized Betas: $\mathrm{a} \leq .001, \mathrm{~b} \leq .01, \mathrm{c} \leq .05 ; N=528$.

Gender: 1 = male, 1 = female.

City: 1 = Milwaukee, 2 = Cleveland.

Minority: 1 = white, 2 = minority.

"Entered without "need to know."

***Entered without current knowledge or sufficient protection knowledge.

judgments relate to perceived uncertainty. Only two of these variables, perceived importance of the issue $(\beta=.13, p=.002)$ and perceived likelihood of coming to harm $(\beta=.07, p=.05)$, are associated with perceived uncertainty in the final model. Several other factors are indirectly associated with uncertainty through other variables. Milwaukee residency $(\beta=-.11$, $p=.01)$, education levels $(\beta=-.11, p=.02)$, income levels $(\beta=-.11, p=.02)$, and race $(\beta=$ $.09, p=.042)$ are significantly associated with uncertainty with other demographics controlled, but these relationships drop to insignificance when issue importance is controlled. Eating fish $(\beta=-.21, p<.001)$ and avoiding all fish $(\beta=.20, p<.001)$ are both significantly associated with perceived uncertainty with demographics controlled, but drop to insignificance when information exposures and government trust (respectively) are controlled. Television exposure $(\beta=.15, p=.001)$, interpersonal discussion $(\beta=.20, p<.001)$, trust in government $(\beta=-.19, p<.001)$, perceived seriousness $(\beta=.39, p<.001)$, and threat to future generations $(\beta=.42, p<.001)$ are significantly associated with perceived uncertainty with only demographics controlled, but drop to insignificance when emotions are controlled. 


\section{Discussion}

\section{How do cognitions and emotions affect perceived uncertainty?}

This study aimed to better understand what factors shape the risk uncertainty perceptions of lay audiences. First and foremost, results show that perceived risk uncertainty is strongly associated with emotions, as other scholars have suggested (Bradac, 2001; Brashers, 2001). Findings also support previous proposals that "not knowing" is a component of perceived uncertainty (Einsiedel and Thorne, 1999; Sorrentino and Roney, 2000). Both lower perceived knowledge and perceived "need to know," another measurement of "not knowing," are weakly but significantly associated with perceived uncertainty.

Regression patterns also raise several questions about the nature of the relationship between perceived knowledge and perceived uncertainty. The negative relationship between knowledge and uncertainty is statistically weak in the final equation. Hierarchical regression patterns, further, indicate that the relationship is not straightforward and is mediated or moderated by several other variables. The relationship between knowledge and uncertainty is positive with demographics controlled, but when fish consumption is added the relationship flips to negative, and when information exposures and emotions are added to the equation, the strength of the relationship increases to significance (remaining negative). These patterns indicate that several variables, particularly emotions, may suppress the relationship between perceived knowledge and uncertainty. Also, the strong positive correlation between perceived current knowledge and sufficient protection knowledge suggests that as people's perceived knowledge levels increase, they tend to feel they need to know more about the risk. This suggests, as others propose, that as perceived knowledge increases, questions and uncertainties may increase as well (Funtowics and Ravetz, 1990; Jaeger et al., 2001).

These results suggest that to understand how perceived knowledge relates to perceived uncertainty, we may need to understand more about the content of people's knowledge, what factors shape this content, and how it relates to information exposures, emotions, and uncertainties. These relationships are discussed further below and, we will argue, should be explored more fully in future research.

\section{How do other social and individual factors affect perceived uncertainty?}

Regression patterns indicate that perceived likelihood of harm and issue importance are directly related to perceived uncertainty while socioeconomic factors, fish consumption, information exposures, and other risk judgments influence uncertainty indirectly. Not surprisingly, many of these variables influence perceived uncertainty because they are related to anger and/or worry about the risk. Because emotions play such an important role in uncertainty perceptions, we regressed emotions separately on key study variables to better understand what factors shape them. Similarly, we regressed perceived knowledge and need to know separately on other variables. Table 3 shows these regression results.

The finding that perceived likelihood of coming to harm is associated with perceived uncertainty (see Table 2) supports previous scholars' proposals that uncertainty includes probabilistic judgments, since perceived likelihood is a type of probability assessment. This relationship holds even with emotions controlled (although it drops considerably, indicating some shared variance). Interestingly, though, levels of perceived likelihood of harm are relatively low overall (mean of 3.4 on a 0 to 10 scale), even among people who reported higher emotion levels. Why are people worried and angry if they don't feel very likely to become ill?

Results shown in Table 3 suggest that people who feel that fish contamination poses a risk to future generations, that it is a serious problem, and who do not trust the government 
Table 3. Predictors to knowledge, emotions and need to know

\begin{tabular}{|c|c|c|c|}
\hline & Knowledge (direct) & Emotions (direct) & Need to know (direct) \\
\hline \multicolumn{4}{|l|}{ Demographics } \\
\hline \multicolumn{4}{|l|}{ City } \\
\hline Age & & & $-.12^{\mathrm{b}}$ \\
\hline Gender & $-.13^{b}$ & & $.12^{\mathrm{b}}$ \\
\hline Education & & $-.10^{\mathrm{b}}$ & \\
\hline Income & & $-.07^{\mathrm{c}}$ & \\
\hline Minority & & $.08^{\mathrm{b}}$ & \\
\hline $\mathbf{R}^{2}$ change & $.05^{\mathrm{a}}$ & $.12^{\mathrm{a}}$ & $.06^{\mathrm{a}}$ \\
\hline \multicolumn{4}{|l|}{ Fish consumption } \\
\hline \multicolumn{4}{|l|}{ Eat fish } \\
\hline \multicolumn{4}{|l|}{ Avoid some fish } \\
\hline \multicolumn{4}{|l|}{ Avoid all fish } \\
\hline $\mathbf{R}^{2}$ change & $.02^{\mathrm{b}}$ & $.08^{\mathrm{a}}$ & .01 \\
\hline \multicolumn{4}{|l|}{ Information exposures } \\
\hline Newspaper & $.10^{\mathrm{c}}$ & & \\
\hline Television & & $.08^{\mathrm{c}}$ & \\
\hline \multicolumn{4}{|l|}{ Radio } \\
\hline Advisories & $-.13^{\mathrm{b}}$ & & $.10^{\mathrm{c}}$ \\
\hline Discussion & $.28^{\mathrm{a}}$ & $.11^{\mathrm{a}}$ & \\
\hline $\mathbf{R}^{2}$ change & $.11^{\mathrm{a}}$ & $.08^{\mathrm{a}}$ & \\
\hline Current knowledge & $\mathrm{NE}$ & & $\mathrm{NE}$ \\
\hline $\mathbf{R}^{2}$ change & $\mathrm{NE}$ & .00 & $\mathrm{NE}$ \\
\hline \multicolumn{2}{|l|}{ Issue importance } & $.36^{\mathrm{a}}$ & \\
\hline $\mathbf{R}^{2}$ change & .01 & $.22^{\mathrm{a}}$ & $.03^{\mathrm{a}}$ \\
\hline \multicolumn{2}{|l|}{ Government trust } & $-.13^{\mathrm{a}}$ & \\
\hline $\mathbf{R}^{2}$ change & .00 & $.02^{\mathrm{a}}$ & \\
\hline \multicolumn{4}{|l|}{ Risk judgments } \\
\hline \multicolumn{4}{|l|}{ Perceived likelihood } \\
\hline Perceived seriousness & & $.14^{\mathrm{a}}$ & \\
\hline Perceived future threat & & $.22^{\mathrm{a}}$ & \\
\hline $\mathbf{R}^{2}$ change & .01 & $.06^{\mathrm{a}}$ & .01 \\
\hline Emotions & & NE & $.13^{\mathrm{c}}$ \\
\hline $\mathbf{R}^{2}$ change & .00 & NE & .01 \\
\hline Total adjusted $\mathbf{R}^{2}$ & .17 & .56 & .11 \\
\hline
\end{tabular}

All coefficients are standardized Betas (final only): $\mathrm{a} \leq .001, \mathrm{~b} \leq .01, \mathrm{c} \leq .05$.

$\mathrm{NE}=$ not entered.

to deal adequately with the problem are more likely to be worried and angry about the issue. These variables, in fact, are more strongly related to emotions than perceived likelihood. In other words, for this risk, which is perceived as a low-level personal risk, people's emotions and uncertainties seem to be based as much on social factors, such as perceived risk to others and perceived government action/inaction, as on individual factors such as perceived personal risk likelihood. This finding parallels previous studies that connect government distrust to risk perceptions and emotions (Cvetkovich et al., 2002; Freudenburg and Pastor, 1992). Would this be the case if a risk were perceived as a high-level personal risk? Future studies should address this question.

Perceived issue importance has an unexpectedly strong relationship with perceived uncertainty (Table 2). Even though risk judgment levels tended to be quite low among respondents, 
issue importance levels were relatively high (mean $=6.6$ on a 10-point scale). Table 3 suggests that its strong relationship with emotions partly explains this relationship; people who tend to be more angry and worried about the issue tend to think the fish risk issue is more important. Do people feel that the issue is important because they are angry and worried about it, or are they angry and worried about it because it is important to them, or both? Interestingly, the relationship between issue importance and uncertainty still holds when emotions are controlled, although it drops in significance (see Table 2). This suggests that issue importance contributes uniquely to perceived uncertainty. Complicating the relationship, bivariate correlations (not shown) suggest that certain kinds of people-less educated, lower income, minorities, and those who avoid all fish-tend to feel that the fish risk issue is more important. These relationships raise questions about why and how the fish risk issue is important to some people and not others, and why perceived importance is associated with perceived uncertainty.

Communication processes also appear to play indirect but significant roles in uncertainty perceptions-primarily through perceived knowledge and emotions (Table 3). Those who said they have more frequent interpersonal discussions about fish contamination are likely to think they know more about the fish risk and are likely to be more worried and angry about the issue. People who said they watch more television are more likely to be worried and angry about the fish risk, and people who spend more time reading the newspaper are likely to feel they know more about the issue. Relationships among media exposures, interpersonal discussions, knowledge, and emotions are undoubtedly multi-directional and dynamic. For example, people may hear friends and family talking about fish risks, which might then increase their worry about the issue. Subsequently, they might pay more attention to future interpersonal discussions and to newspaper articles about the issue when they come across them, which might increase their perceived knowledge about the issue. Increased perceived knowledge could then influence their emotions and uncertainty perceptions-and subsequent information and interpersonal discussion interactions-in a variety of ways. Knowing more about what kinds of mediated information people are interacting with and what kinds of interpersonal discussions they are engaging in would help us better understand these relationships.

Last but not least, Table 3 indicates that contextual and sociodemographic factors may play indirect but important roles in shaping uncertainty perceptions. For example, people who avoid all fish are significantly more likely to be worried and angry about the issue, and people who eat fish (and don't avoid any) are significantly less likely to be worried about it. Perhaps people who are not worried about fish toxins are more likely to eat fish, and people who are worried are more likely to avoid the fish. These findings could also reflect defensive attitudes among fish consumers about the risks they face (Weinstein, 1989). Regressions also suggest that fish consumption is related to perceived uncertainty indirectly, but interestingly, the connection does not appear to be mediated or moderated by emotions. People who eat fish are significantly less likely to be uncertain, but when information exposures are controlled the relationship drops to insignificance. This suggests that interactions with information and/or interpersonal discussion among fish consumers may be lowering their perceived uncertainty about the risks. People who avoid fish, on the other hand, are significantly more likely to be uncertain, but when government trust is controlled, the relationship drops to insignificancesuggesting that among fish avoiders, government mistrust may heighten risk uncertainties.

Finally, racial minorities, lower income and less educated people are more likely to report higher levels of worry and anger about fish contamination. Women are likely to say they know less about the fish risk, are more worried about it, feel more likely to become ill, and need to know more-all factors that relate significantly to perceived uncertainty. The finding that women and minorities are more concerned about health risks parallels previous research (Bord and O'Connor, 1997; Finucane, 2002). Although scholars haven't reached firm conclusions about 
why this relationship is found so consistently, some speculate that women and minorities tend to feel more vulnerable to risks than white men (Bord and O'Connor, 1997).

\section{Conclusions}

What is perceived risk uncertainty? This study joins previous work in suggesting that perceived risk uncertainty is strongly associated with negative emotions such as worry and anger and, to a lesser degree, reflects a sense of "not knowing." Results also suggest that several factors not considered in previous studies may influence perceived uncertainty in significant ways and should be considered in future studies: (1) the content of perceived knowledge about risks; (2) social perceptions (e.g., trust in government, perceived risk to others); (3) perceived issue importance; (4) interactions with mediated information and interpersonal discussions; and (5) socioeconomic and contextual factors.

Study findings also raise some methodological questions. Clearly, hierarchical regressions reveal important patterns in relationships among key study variables. At the same time, however, results raise several questions that might be more thoroughly addressed using qualitative approaches designed to explore physical, cultural, and social contexts and how these contexts relate to the content of people's knowledge, emotions, and uncertainties. What kinds of things do people know and not know about health risks, and how do "knowing" and "not knowing" affect their emotions and uncertainties about the risks? Even more basically, how does "knowing" relate to "not knowing" about risks?

What different kinds of uncertainties do people perceive about risks? Why do people of different races, genders, and with different income levels think and feel differently about health risks? How do social, cultural, and physical experiences and contexts-and interactions with different kinds of information and interpersonal discussions-influence people's knowledge, emotions, issue importance, and perceived uncertainties?

Although some of these questions and contextual factors can be assessed using quantitative survey methods, local contexts and experiences are difficult to examine using phone or mail surveys. Future studies could more meaningfully address these questions using qualitative approaches (Campbell and Russo, 2001; Flyvberg, 2001).

\section{References}

Adeola, F.O. (2000) "Endangered Community, Enduring People: Toxic Contamination, Health, and Adaptive Responses in a Local Context," Environment and Behavior 32(2): 209-49.

Arcury, T.A., Quandt, S.A. and Russell, G.B. (2002) "Pesticide Safety among Farmworkers: Perceived Risk and Perceived Control as Factors Reflecting Environmental Justice," Environmental Health Perspectives 110(2): 233-40.

Babrow, A.S., Kasch, C.R. and Ford, L.A. (1998) "The Many Meanings of Uncertainty in Illness: Toward a Systematic Accounting," Health Communication 10(1): 1-23.

Beehler, G.P., McGuiness, B.M. and Vena, J.E. (2001) "Polluted Fish, Sources of Knowledge, and the Perception of Risk: Contextualizing African American Anglers' Sport Fishing Practices," Human Organization 60(3): $288-97$.

Berger, C.R. (1987) "Communicating under Uncertainty," in M.E. Roloff and G.R. Miller (eds) Interpersonal Processes: New Directions in Communication Research, pp. 39-62. Beverly Hills, CA: SAGE.

Bord, R.J. and O'Connor, R.E. (1997) "The Gender Gap in Environmental Attitudes: The Case of Perceived Vulnerability to Risk," Social Science Quarterly 78(4): 831-40.

Bradac, J.J. (2001) "Theory Comparison: Uncertainty Reduction, Problematic Integration, Uncertainty Management, and other Curious Constructs," Journal of Communication 51(3): 456-76.

Brashers, D.E. (2001) “Communication and Uncertainty Management," Journal of Communication 51(3): 477-97.

Brashers, D.E., Hass, S.M., Klingle, R.S. and Neidig, J.L. (2000a) "Collective AIDS Activism and Individuals' Perceived Self-Advocacy in Physician-Patient Communication," Human Communication Research 26: $372-402$. 
Brashers, D.E., Neidigg, J.L., Haas, S.M., Dobbs, L.K., Cardillo, L.W. and Russell, J.A. (2000b) "Communication in the Management of Uncertainty: The Case of Persons Living with HIV or AIDS," Communication Monographs 67: 63-84.

Brown, P. and Mikkelson, E. (1990) No Safe Place: Toxic Waste, Leukemia, and Community Action. Berkeley, CA: University of California Press.

Bullard, R. (1990) Dumping in Dixie: Race, Class, and Environmental Quality. Boulder, CO: Westview Press.

Burger, J. (2000) "Consumption Advisories and Compliance: The Fishing Public and the Deamplification of Risk," Journal of Environmental Planning and Management 43(4): 471-88.

Burger, J., Stephens, W.L., Jr., Boring, C.S., Kuklinski, J., Givvons, J.W. and Gochfeld, J. (1999) "Factors in Exposure Assessment: Ethnic and Socioeconomic Differences in Fishing and Consumption of Fish Caught along the Savannah River," Risk Analysis 19(3): 427-38.

Bush, J., Moffatt, S. and Dunn, C. (2001) "Keeping the Public Informed? Public Negotiation of Air Quality Information," Public Understanding of Science 10: 213-29.

Campbell, B.L. (1985) "Uncertainty as Symbolic Action in Disputes among Experts," Social Studies of Science 15: 429-53.

Campbell, D.T. and Russo, M.J., eds (2001) Social Measurement. London: SAGE.

Chaffee, S.H. and Mutz, D.C. (1988) "Comparing Mediated and Interpersonal Communication Data," in R.P. Hawkins, J.M. Wiemann and S. Pingree (eds) Advancing Communication Science: Merging Mass and Interpersonal Processes, pp. 19-43. Newbury Park, CA: SAGE.

Chiarappa, M.J. and Szylvian, K.M. (2003) Fish for All: An Oral History of Multiple Claims and Divided Sentiment on Lake Michigan. East Lansing, MI: Michigan State University Press.

Coleman, C. (1993) "The Influence of Mass Media and Interpersonal Communication on Societal and Personal Risk Judgments," Communication Research 20(4): 611-28.

Courval, J.M., De Hoof, J.V., Stein, A.D., Tay, E.M., He, J. and Humphrey, H. (1999) "Sport-Caught Fish Consumption and Conception Delay in Licensed Michigan Anglers," Environmental Research 80: S183-S188.

Cvetkovich, G.C., Siegrist, M., Murray, R. and Tragesser, S. (2002) "New Information and Social Trust: Asymmetry and Perseverance of Attributions about Hazard Managers," Risk Analysis 22(2): 359-67.

Darvill, T., Lonky, E., Reihman, J. and Daly, H. (1996) "Critical Issues for Research on the Neurobehavioral Effects of PCBs in Humans," Neurotoxicology and Teratology 18(3): 265-70.

DiPerna, P. (1985) Cluster Mystery: Epidemic and the Children of Woburn, Mass. New York: Mosby.

Eagly, A.H. and Chaiken, S. (1993) The Psychology of Attitudes. San Diego, CA: Harcourt Brace.

Einsiedel, E. and Thorne, B. (1999) "Public Responses to Uncertainty," in S.M. Friedman, S. Dunwoody and C.L. Rogers (eds) Communicating Uncertainty: Media Coverage of New and Controversial Science, pp. 43-57. Mahwah, NJ: Lawrence Erlbaum Associates.

Ferguson, E. (2001) "The Roles of Contextual Moderation and Personality in Relation to the Knowledge-Risk Link in the Workplace," Journal of Risk Research 4(4): 323-40.

Festinger, L. (1954) "A Theory of Social Comparison Processes," Human Relations 7: 117-40.

Festinger, L. (1957) A Theory of Cognitive Dissonance. Stanford, CA: Stanford University Press.

Finucane, M. (2002) "Mad Cows, Mad Corn and Mad Communities: The Role of Socio-Cultural Factors in the Perceived Risk of Genetically-modified Food," Proceedings of the Nutrition Society 61: 31-7.

Finucane, M.L., Alhakami, A., Slovic, P. and Johnson, S.M. (2000) "The Affect Heuristic in Judgments of Risks and Benefits," Journal of Behavioral Decision Making 13: 1-17.

Flyvberg, B. (2001) Making Social Science Matter: Why Social Inquiry Fails and How It Can Succeed Again. Cambridge: Cambridge University Press.

Freudenburg, W.R. and Pastor, S.K. (1992) "Public Responses to Technological Risks: Toward a Sociological Perspective," The Sociological Quarterly 33(3): 389-412.

Frewer, L.J., Shepherd, R. and Sparks, P. (1994) "The Interrelationship between Perceived Knowledge, Control and Risk Associated with a Range of Food-related Hazards Targeted at the Individual, other People and Society," Journal of Food Safety 14: 19-40.

Frewer, L.J., Hunt, S., Miles, S., Brennan, M., Kusnesoff, S., Ness, M. and Ritson, C. (2001) "Communicating Risk Uncertainty with the Public," Final Report and Technical Annex to the Final Report for the UK Food Standards Agency. Norwich: Institute of Food Research.

Frewer, L.J., Miles, S., Brennan, M., Kunesoff, S., Ness, M. and Ritson, C. (2002) "Public Preferences for Informed Choice under Conditions of Uncertainty," Public Understanding of Science 11: 363-72.

Frewer, L.J., Hunt, S., Brennan, M., Kuznesof, S., Ness, M. and Ritson, C. (2003) "The Views of Scientific Experts on How the Public Conceptualize Uncertainty," Journal of Risk Research 6(1): 75-85.

Friedman, S.M., Dunwoody, S. and Rogers, C.L., eds (1999) Communicating Uncertainty: Media Coverage of New and Controversial Science. Mahwah, NJ: Lawrence Erlbaum Associates. 
Funtowics, S.O. and Ravetz, J.R. (1990) Uncertainty and Quality in Science for Policy. Theory and Decision Library, Series A 15. Dordrecht: Kluwer.

Griffin, R J., Dunwoody, S. and Neuwirth, K. (1999) "Proposed Model of the Relationship of Risk Information Seeking and Processing to the Development of Preventive Behaviors," Environmental Research 80: S230-S245.

Hallman, W.K. and Wandersman, A. (1992) "Attribution of Responsibility and Individual and Collective Coping with Environmental Threats," Journal of Social Issues 49(4): 101-18.

Hansen, A. (1993) The Mass Media and Environmental Issues. New York: Leicester University Press.

Harding, S. (1998) Is Science Multicultural? Postcolonialisms, Feminisms, and Epistemologies. Bloomington, IN: Indiana University Press.

Heider, F. (1958) The Psychology of Interpersonal Relations. New York: Wiley.

Heyman, B., Henrikesen, M. and Maughan, K. (1998) "Probabilities and Health Risks: A Qualitative Approach," Social Science and Medicine 47: 1295-306.

Hornig Priest, S. (2001) A Grain of Truth: The Media, the Public, and Biotechnology. New York: Rowman and Littlefield.

Howel, D., Moffatt, S., Prince, H., Bush, J. and Dunn, C.E. (2002) "Urban Air Quality in North-East England: Exploring the Influences on Local Views and Perceptions," Risk Analysis 22(1): 121-30.

Humphrey, H.E.B., Gardiner, J.C., Pandya, J., Sweeney, A., Gasior, D.M., McCaffrey, R.J. and Schantz, S.L. (2000) "PCB Congener Profile in the Serum of Humans Consuming Great Lakes Fish," Environmental Health Perspectives 108(2): 167-72.

Irwin, A. and Wynne, B. (1996) Misunderstanding Science? The Public Reconstruction of Science and Technology. Cambridge: Cambridge University Press.

Jacobson, J.L. and Jacobson, S.W. (1996) "Intellectual Impairment in Children Exposed to Polychlorinated Biphenyls in Utero," New England Journal of Medicine 335(11): 783-9.

Jaeger, C.C., Renn, O., Rosa, E.A. and Webler, T. (2001) Risk, Uncertainty, and Rational Action. Sterling, VA: Earthscan.

Johnson, B.B. (2003a) "Are Some Risk Comparisons More Effective under Conflict? A Replication and Extension of Roth et al.," Risk Analysis 25(4): 767-80.

Johnson, B.B. (2003b) "Further Notes on Public Response to Uncertainty in Risks and Science," Risk Analysis 23(4): 781-9.

Johnson, B.B. and Slovic, P. (1995) "Presenting Uncertainty in Health Risk Assessment: Initial Studies of its Effects on Risk Perception and Trust," Risk Analysis 15: 485-94.

Johnson, B.B. and Slovic, P. (1998) "Lay Views on Uncertainty in Environmental Health Risk Assessment," Journal of Risk Research 1: 261-79.

Kahneman, D. and Tversky, A. (1982a) "Variants of Uncertainty," Cognition 11: 143-57.

Kahneman, D. and Tversky, A. (1982b) “The Simulation Heuristic," in D. Kahneman, P. Slovic and A. Tversky (eds) Judgment Under Uncertainty: Heuristics and Biases. New York: Cambridge University Press.

Lindbladh, E. and Lyttkens, C.H. (2003) "Polarization in the Reaction to Health-Risk Information: A Question of Social Position," Risk Analysis 23(4): 841-55.

Lopez, R. (2002) "Segregation and Black/White Differences in Exposure to Air Toxics in 1990," Environmental Health Perspectives (Supplements) 110(2): 289-95.

Matthies, E., Hoger, R. and Guski, R. (2000) "Living on Polluted Soil: Determinants of Stress Symptoms," Environment and Behavior 32(2): 270-86.

Miles, S. and Frewer, L.J. (2003) "Public Perception of Scientific Uncertainty in Relation to Food Hazards," Journal of Risk Research 6(3): 267-83.

Mohai, P. and Bryant, B., eds (1992) Race and the Incidence of Environmental Hazards: A Time for Discourse. Boulder, CO: Westview.

Nerb, J. and Spada, H. (2001) "Evaluation of Environmental Problems: A Coherence Model of Cognition and Emotion," Cognition and Emotion 15(4): 521-51.

O'Keefe, G., Ward, H.J. and Shepard, R. (2002) "A Repertoire Approach to Environmental Information Channels," Science Communication 23(4): 392-409.

Petty, R.E. and Cacioppo, J.T. (1981) Attitudes and Persuasion: Classic and Contemporary Approaches. Dubuque, IA: Brown.

Rice, D.C. (1995) "Neurotoxicity of Lead, Methylmercury and PCBs in Relation to the Great Lakes," Environmental Health Perspectives 103(Suppl 9): 71-87.

Rimal, R.N., Flora, J.A. and Schooler, C. (1999) "Achieving Improvements in Overall Health Orientation: Effects of Campaign Exposure, Information Seeking, and Health Media Use," Communication Research 26(3): $322-48$.

Rowsell, B., Norris, P., Ryan, K. and Weenink, M. (2000) "Assessing and Managing Risk and Uncertainty: Women Living with Breast Implants,” Health, Risk and Society 2(2): 205-18. 
Shatenstein, B., Kosatsky, T., Nadon, S., Lussier-Carn, S. and Weber, J.P. (1999) "Reliability and Relative Validity of Fish Consumption Data Obtained in an Exposure Assessment Study among Montreal-Area Sportfishers," Environmental Research Section A80: S71-S86.

Slovic, P. (1992) "Perception of Risk: Reflections on the Psychometric Paradigm," in S. Krimsky and D. Golding (eds) Social Theories of Risk, pp. 117-52. Westport, CT: Praeger.

Slovic, P., Peters, E., Finucane, M.L. and MacGregor, D.G. (2005) “Affect, Risk, and Decision Making," Health Psychology 24: S35-S40.

Smith, C.A., Haynes, K.N., Lazarus, R.S. and Pope, L.K. (1993) "In Search of the 'Hot' Cognitions: Attributions, Appraisals, and their Relation to Emotion,” Journal of Personality and Social Psychology 65(5): 916-29.

Smithson, M. (1989) Ignorance and Uncertainty: Emerging Paradigms. New York: Springer-Verlag.

Sorrentino, R.M. and Roney, C.J.R. (2000) The Uncertain Mind: Individual Differences in Facing the Unknown. Philadelphia, PA: Psychology Press.

Stocking, S.H. and Holstein, L.W. (1993) "Constructing and Reconstructing Scientific Ignorance: Ignorance Claims in Science and Journalism," Knowledge: Creation, Diffusion, Utilization 15(2): 186-210.

Thompson, E.P. and Kruglanski, A.W. (2000) Why We Evaluate: Functions of Attitudes. Mahwah, NJ: Lawrence Erlbaum Associates.

Tilden, J., Hanrahan, L.P., Anderson, H., Palit, C., Olson, J., MacKenzie, W. and the Great Lakes Sport Fish Consortium (1997) "Health Advisories for Consumers of Great Lakes Sport Fish: Is the Message Being Received?," Environmental Health Perspectives 105(12): 1360-5.

Valente, T.W. and Saba, W.P. (1998) "Mass Media and Interpersonal Influence in a Reproductive Health Communication Campaign in Bolivia," Communication Research 25(1): 96-124.

Weary, G. and Edwards, J.A. (1994) "A Measure of Dispositional Causal Uncertainty," Journal of Personality and Social Psychology 67: 308-18.

Weary, G. and Edwards, J.A. (1996) “Causal-Uncertainty Beliefs and Related Goal Structures," in R.M. Sorrentino and E.T. Higgins (eds) Handbook of Motivation and Cognition, Volume 3. New York: Guilford Press.

Weary, G. and Jacobson, J.A. (1997) "Causal Uncertainty Beliefs and Diagnostic Information Seeking," Journal of Personality and Social Psychology 73(4): 839-48.

Weinstein, N. (1989) "Optimistic Biases about Personal Risks," Science 246: 1232-3.

Wood, W., Rhodes, N. and Biek, M. (1995) "Working Knowledge and Attitude Strength: An Information-Processing Analysis," in R.E. Petty and J.A. Krosnick (eds) Attitude Strength: Antecedents and Consequences, pp. 283-314. Mahwah, NJ: Lawrence Erlbaum Associates.

Wynne, B. (1980) “Technology, Risk and Participation: On the Social Treatment of Uncertainty," in J. Conrad (ed.) Society, Technology, and Risk Assessment. Frankfurt, Germany: Academic Press.

Wynne, B. (2001) "Creating Public Alienation: Expert Cultures of Risk and Ethics on GMOs," Science as Culture 10(4): 445-81.

\section{Authors}

Maria Powell is an Assistant Scientist with the Nanoscale Science and Engineering Center and the Nelson institute for Environmental studies. Her doctoral research focused on lay uncertainties about health risks related to the consumption of contaminated Great Lakes fish. Her current research explores environmental and health risks related to nanotechnologies and the ways uncertainties and data gaps about these risks are shaped by interactions among individual, scientific, political, and societal processes. Correspondence: Nelson Institute for Environmental Studies, 550 North Park St., 10 Science Hall, University of Wisconsin, Madison, WI 53706-1491 e-mail: powell@wisc.edu

Sharon Dunwoody is Evjue-Bascom Professor of Journalism and Mass Communication and Associate Dean for Social Studies in the Graduate School at the University of WisconsinMadison. Her research focuses on the role of information in lay risk judgments and on media coverage of science generally. Most recently, she has been part of a five-country survey of scientists' perceptions of media science coverage and of their own popularization activities. 
Robert J. Griffin is full professor in the Diederich College of Communication at Marquette University in Milwaukee, Wisconsin, and director of its Center for Mass Media Research. His teaching and research interests focus on communication about environmental issues, energy, health, science, and risk. He has been principal investigator or co-PI for federally funded research into environmental risks and has recently served on a National Research Council standing committee concerned with emerging issues in environmental contamination.

Kurt Neuwirth (Ph.D., 1995, University of Wisconsin-Madison) is an Associate Professor in the Department of Communication at the University of Cincinnati. His research interests include risk communication and processes and effects of public opinion. 